San Antonio Review • San Antonio Review (Volume IV | Fall 2020)

\title{
Art by Alexandra S. Machuca
}

\author{
Alexandra S. Machuca
}

Published on: Nov 30, 2020

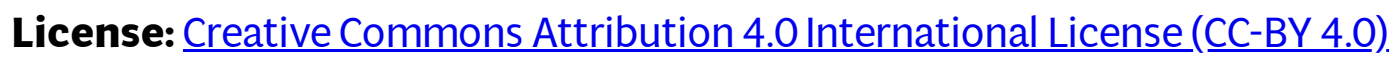


Alexandra S. Machuca's painting "Revolucion" (below) is featured as cover art on San Antonio Review (Volume IV, Fall 2020).

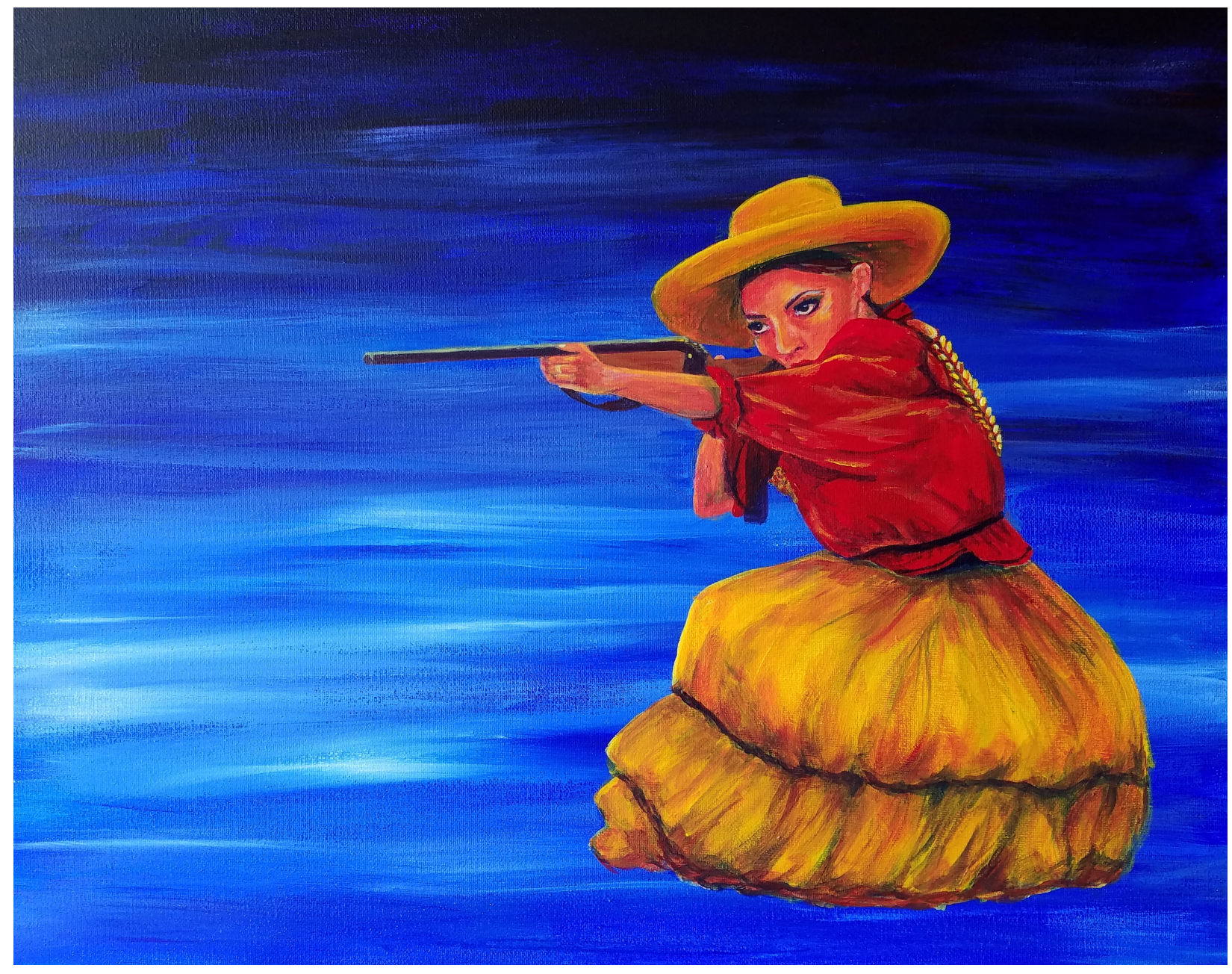

"Revolución," Acrylic on canvas, 16×20, Alexandra S. Machuca

Based on an image from Amalia Hernández's Ballet Folklorico de México (revolución), the piece was created as a healing process regarding the political situation of the United States at the time. 


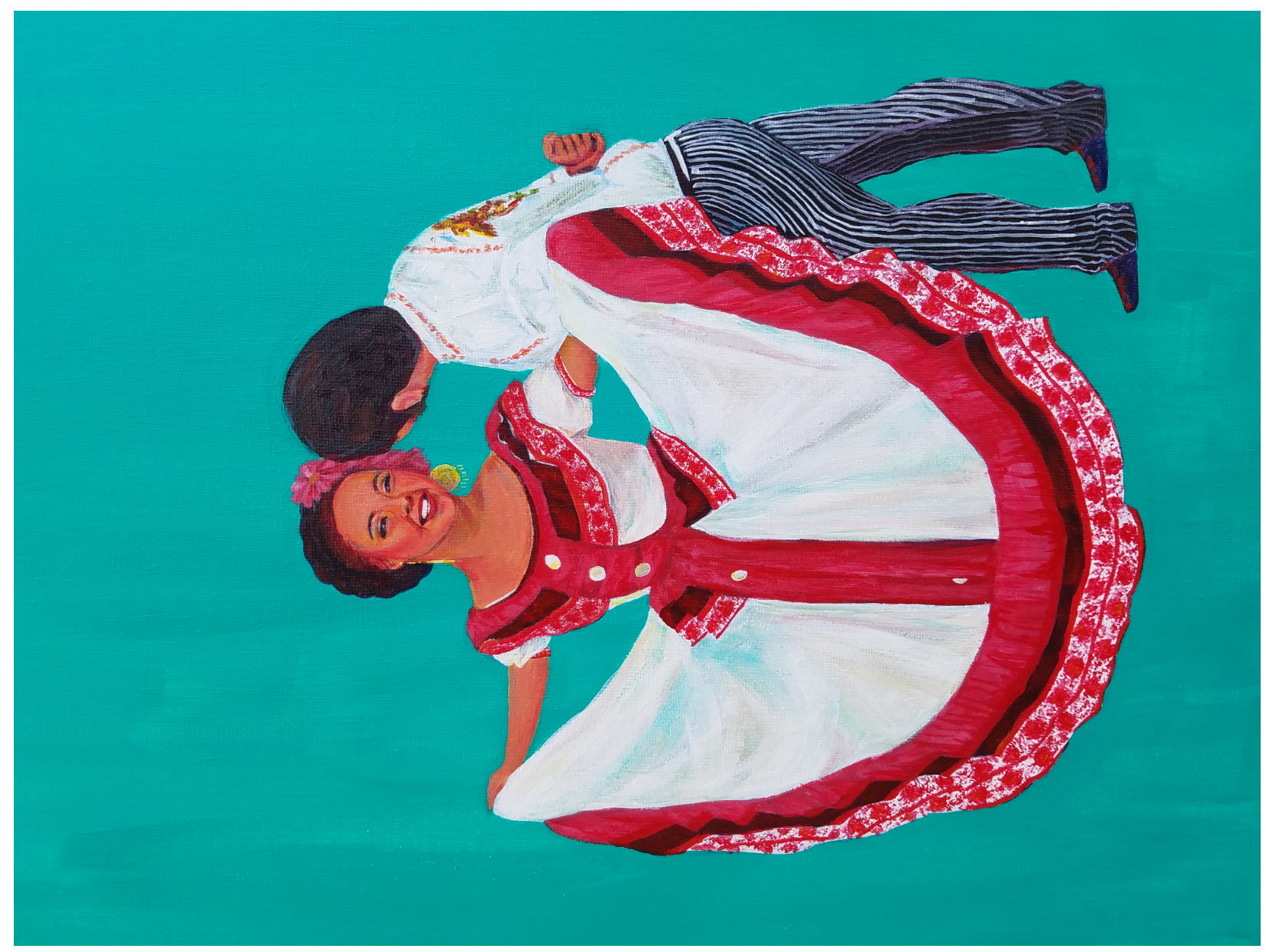

"Jemzi and Tony, Colima," Acrylic on canvas, $16 \times 20$, Alexandra S. Machuca

Jemzi and Tony are a couple from UCSC who performed the region of Colima, Mexico in 2019. 


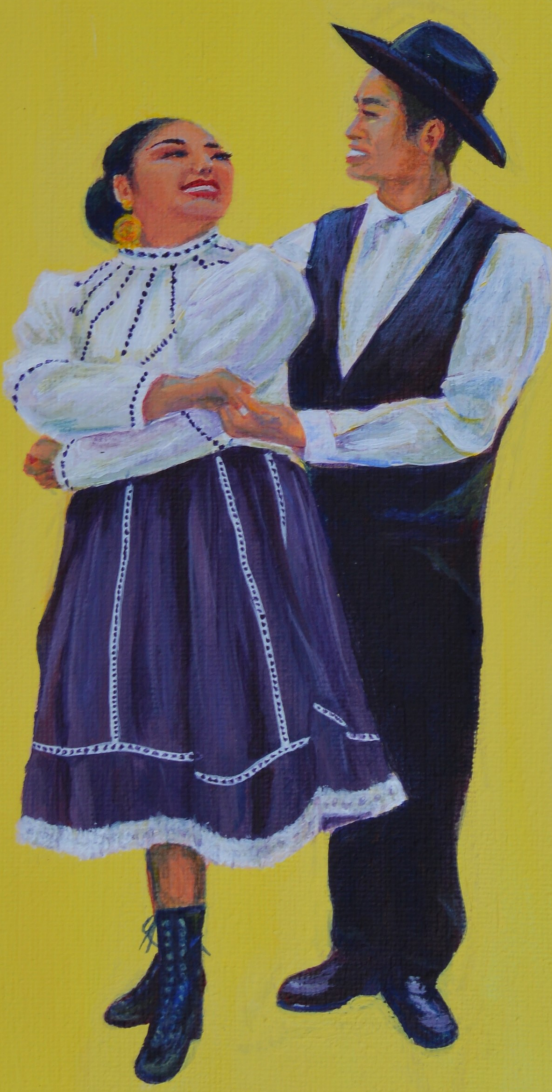

Genesis and Hung were two UCSC Grupo Folklórico students and dancers who performed the region of Chihuahua, Mexico. 


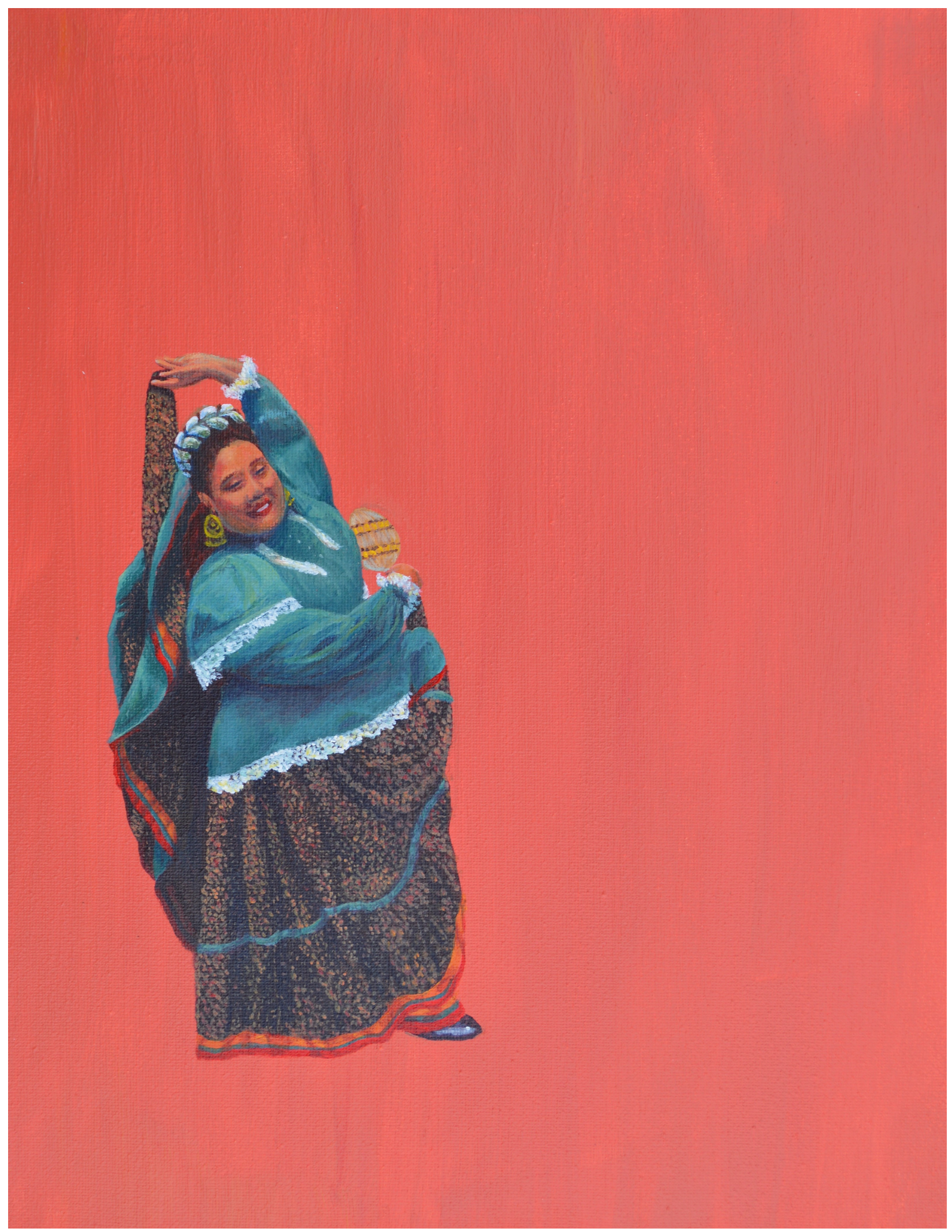


This portrait was based on a photo taken of Wendy after her first performance of Nayarit Mestizo.

Alexandra S. Machuca is a Xicana artist who lives in Bakersfield, California. She recieved a BA in Studio Art from the University of California Santa Cruz and is in the process of applying to law school. Predominantly an acrylic painter, the subjects she chooses revolve around individual members of communities whether they are of her own or admired in their own. None of her pieces are commissions and are often made dedicated to those whose image is presented on the canvas/paper or for friends and colleagues. She expresses that each piece is made with love and an anticapitalist spirit. 